chelonians. Ponds, creeks, marshes and rivers are swarming with them, and surely a place could be found which only requires fencing to be turned into a scientific, experimental ' crawl,' where some hundreds of turtles of a suitable kind could be turned loose, labeled, of course, and examined from time to time whether any of them are amending their abnormal shells. For physical reasons such an experiment of possibly far-reaching, fundamental importance, can not be made in Europe. H. GADOW.

Cambridge, Eng., September 4, 1905.

\section{NOTE ON VECTOR SYMBOLS.}

The question of notation was always of importance, and the introduction of new methods depends a good deal on it. It is, of course, highly desirable to have one system of notation used by all the scientific world, but at the same time it is also desirable that the system in use shall be a simple and easy one.

The vector-analysis becomes more important every day in the study of physics. It is, therefore, necessary to have a vector notation as simple as possible. The notation used today is far from being uniform, and still the tendency is towards the introduction of German letters for the symbolization of vectors. May be that when printed, the German letters look well, and are well distinguished from the Latin alphabet. The student, no matter of what nationality, can learn to recognize them just as he learns to recognize the Greek alphabet. But the question is the writing of the German characters. Those that try to picture a German print-letter on the board when necessary to use the vector symbols in a lecture before a class will know how difficult this is. And to use different signs when written and different signs when printed does not seem reasonable. Why not use as symbols for vector quantities the Latin alphabet? The Latin alphabet is almost universal; and there is no difficulty whatever to write this alphabet. I, therefore, propose-with Professor Karl Heun in Germany-to use the following notation for vectors, a notation as simple as it can be.
All vector quantities are written as follows: $\bar{a}, \bar{b}, \bar{d}, \cdots, \bar{A}, \bar{B}, G, \cdots$, and their tensors respectively: $a, b, d, \cdots, A, B, G, \cdots$. The scalar-product of two vectors $\bar{a}$ and $b$ is written: $\bar{a} \bar{b}$, which, by definition, is $=a b \cos (a, \bar{b})$. The vector-product of two vectors $\bar{a}, \bar{b}$ is written thus: $\bar{a} \bar{b}$, and because it is itself a vector it can be written: $c=\overline{a b}$. The tensor of this vector: $c=a b \sin (\bar{a}, \bar{b})$. The unit vector can be written, for instance, $\bar{a}_{1}, \bar{b}_{1}, \cdots$, so that $\bar{a}=a \bar{a}_{1}, \bar{e}=e \bar{e}_{1}, \cdots$.

The advantage and simplicity of this system of notation speak for themselves.

\section{H. SCHAPPER.}

\section{UnIVERSITy OF ARKaNSAS, FAYeTteVILle, ARK., August 8, 1905.}

THE OCCURRENCE OF ICHTHYOSAUR-LIKE REMAINS IN THE UPPER CRETACEOUS OF WYOMING.

Through the kindness of Professor S. W. Williston, I have recently received two fragmentary vertebræ found by Mr. W. H. Reed in the Benton Cretaceous near the north end of Medicine Bow Mountains. Although very fragmentary, these vertebræ appear to represent a genus allied to Ichthyosaurus. As this reptilian group has not been known in North America in beds as late as the Benton, the discovery is of considerable interest.

The larger fragment consists of the upper three fourths of a deeply biconcave vertebral centrum apparently from the cervical or anterior dorsal region. The centrum is very thin antero-posteriorly, and in this respect somewhat resembles the corresponding centra in Baptanodon discus. The sides are considerably damaged, so that it is not possible to make a definite statement concerning the rib articulation, but it seems to have been double, as in Baptanodon. A foramen close to the upper end of the diapophyses is larger than any $I$ have seen in this position in the typical Ichthyosaurs, and adds somewhat to the difficulty of making a definite determination of the relationships of this form.

When more material is available it will be interesting to learn whether this form really represents a true Ichthyosaurus or possibly a more highly specialized form of Baptanodon 
than those which we know from the Baptanodon beds. Should it be Baptanodon, it will probably show some extreme specializations, as the time separating the Benton from the Baptanodon beds is considerable.

JoHn C. MERriam.

\section{QUOTATIONS.}

TRUSTEES AND FACULTIES.

The Review is greatly interested to learn that a national congress of the trustees of American universities is to be held this month at the University of Illinois in connection with the inauguration of its new president, and that this conference will be devoted to a discussion of the best form of administration of higher educational institutions and of the proper share of trustees, faculty and alumni in their government. Such a discussion is of especial interest at this time to institute men because of the unfortunate divergence in opinion of the corporation and faculty as to the future educational policy of the institute, and because of the absence of any intermediate body or other means of conference by which an intimate exchange of opinions might take place, and the differences in point of view of the two bodies might be reconciled or compromised.

Whatever be desirable from an ideal standpoint, the practical conditions surrounding American education, especially the legal requirements and the constant need of renewed financial support, will undoubtedly make necessary the existence of a board of trustees in our educational institutions. The proper relations of such a board to the faculty and alumni is a large question, and one which must receive a somewhat different answer in different institutions. The Review believes, however, that the following general principles are vital to the soundness of our educational system. The board of trustees and the faculty must be coordinate bodies, the latter being in no sense subordinate to the former. There must be as sharp a division of functions as is practicable, the trustees dealing exclusively and finally with legal and financial questions, and with the appointments of president and faculty; and the faculty having exclusive jurisdiction in purely educational questions, including not merely the details of instruction, administration and student government, but all matters relating to curriculum, courses of study offered and degree requirements. General questions as to educational aims, and all the numerous questions involving both financial and educational considerations should be discussed by both bodies, and should be acted upon only after substantial agreement has been reached. And to this end there must be established conditions of harmonious cooperation and frequent opportunities for intimate contact and exchange of views. This would seem to be best obtained by the formation of an advisory council-consisting of five or six members from each body, with the president as chairman-which, after thorough discussion should make recommendations both to the trustees and to the faculty. Finally, the alumni not only should be urged to participate in the conduct of the social and athletic life of the students, and to recommend improvements in the courses of study, but they should also be given some direct and substantial share in the government of the institution.-The Technology Review.

\section{THE RHODES SCHOLARSHIPS.}

THe opening of the present term at Oxford will add 67 new scholars to the list of those in residence under the bequest of the late Cecil Rhodes. Allowing for the withdrawal of a few of the German scholars who find it more in accord with their University system at home to take only a two years' course instead of the three years to which the scholarship entitles them, there remain over from last year's students 79 , so that for the academic year 1905-6 the whole number in residence will be slightly under 150. The full list is not, however, yet complete. In 1906, when scholars are elected only for the Colonies and Germany, there will be a further addition of more than 30. As several of the communities concerned have in the last two years failed to send forward a candidate qualified to enter Oxford,

${ }^{1}$ The London Times. 